\title{
Análise epidemiológica do perfil bacteriano envolvido nas Doenças Transmitidas por Alimentos (DTA), na região Nordeste do Brasil para o ano de 2019
}

\author{
Epidemiological analysis of the bacterial profile involved in Foodlborne Diseases (DTA) in the
}

Northeast region of Brazil for the year 2019

Análisis epidemiológico del perfil bacteriano involucrado en Enfermedades Transmitidas por

Alimentos (DTA) en la región Nordeste de Brasil para el año 2019

Recebido: 25/08/2021 | Revisado: 30/08/2021 | Aceito: 02/09/2021 | Publicado: 05/09/2021

\author{
Francinete Sousa de Oliveira \\ ORCID: https://orcid.org/0000-0001-7171-1828 \\ Faculdade de Ensino de Minas Gerais, Brasil \\ E-mail: Fransouoliveira@gmail.com
}

\begin{abstract}
Resumo
Este estudo procurou avaliar o perfil bacteriano envolvido nas Doenças Transmitidas por Alimentos (DTA), na região Nordeste do Brasil para o ano de 2019, e além disso, identificar quais estados desta região apresentaram o maior número de notificações por DTA, assim como investigar os locais e os alimentos onde estes surtos ocorrem com maior frequência. Trata-se de um estudo descritivo de abordagem qualitativa e para isso se utilizou dados do Sistema de Informação de Agravos de Notificação (SINAN), estas informações foram organizadas em tabelas e em seguida realizada a análise de conteúdo. Os resultados apontaram que as cepas bacterianas mais identificadas nos surtos foram: Escherichia coli (62\%), Staphylococcus aureus (14\%) e Salmonela (7\%) e o estado da região Nordeste, onde foi registrado o maior número de surtos foi Pernambuco (82\%), o local de maior incidência de contaminações foram as residências $(60 \%)$ e a água (62\%) foi apontada como sendo o principal veículo de contaminação. Portanto, as informações obtidas nesta pesquisa podem servir de apoio para a adoção de políticas necessárias para o controle destas doenças na região Nordeste, e a promoção de maiores investimentos em ações educativas e legislativas e que trabalhos como este que envolvam outras regiões seria de extrema relevância, pois assim seria possível verificar a realidade de cada região do Brasil.
\end{abstract}

Palavras-chave: Doenças transmitidas por alimentos; Bactérias; Nordeste brasileiro.

\begin{abstract}
This study sought to assess the bacterial profile involved in Foodborne Diseases (FED) in the Northeast region of Brazil for the year 2019, and also to identify which states in this region had the highest number of notifications for DTA, as well as to investigate the places and foods where these outbreaks occur most frequently. This is a descriptive study with a qualitative approach and data from the Information System for Notifiable Diseases (SINAN) was used, this information was organized in tables and then content analysis was performed. The results showed that the bacterial strains most identified in the outbreaks were: Escherichia coli (62\%), Staphylococcus aureus (14\%) and Salmonela (7\%) and the state of the Northeast region, where the highest number of outbreaks was recorded was Pernambuco (82\%), the place with the highest incidence of contamination was homes $(60 \%)$ and water $(62 \%)$ was identified as the main vehicle of contamination. Therefore, the information obtained in this research can support the adoption of necessary policies for the control of these diseases in the Northeast region, and the promotion of greater investments in educational and legislative actions, and that work like this involving other regions would be extremely relevant, because that way it would be possible to verify the reality of each region of Brazil.
\end{abstract}

Keywords: Foodborne diseases; Bacteria; Brazilian northeast.

\section{Resumen}

Este estudio buscó evaluar el perfil bacteriano involucrado en Enfermedades Transmitidas por Alimentos (FED) en la región Nordeste de Brasil para el año 2019, y además, identificar qué estados de esta región tenían el mayor número de notificaciones de DTA, así como investigar los lugares y alimentos donde estos brotes ocurren con mayor frecuencia. Se trata de un estudio descriptivo con enfoque cualitativo y se utilizó información del Sistema de Información de Enfermedades Notificables (SINAN), esta información se organizó en tablas y luego se realizó el análisis de contenido. Los resultados mostraron que las cepas bacterianas más identificadas en los brotes fueron: Escherichia coli (62\%), Staphylococcus aureus (14\%) y Salmonela (7\%) y el estado de la región Nordeste, donde se registró el mayor número de brotes fue Pernambuco (82\%), el lugar con mayor incidencia de contaminación fueron las viviendas (60\%) y el agua 
(62\%) se identificó como el principal vehículo de contaminación. Por tanto, la información obtenida en esta investigación puede apoyar la adopción de las políticas necesarias para el control de estas enfermedades en la región Nordeste, y la promoción de mayores inversiones en acciones educativas y legislativas, y que un trabajo como este involucrando a otras regiones sería de suma relevancia porque de esa manera sería posible verificar la realidad de cada región de Brasil.

Palabras clave: Enfermedades transmitidas por alimentos; Bacterias; Nordeste brasileño.

\section{Introdução}

Doenças transmitidas por alimentos (DTA) são todos os acontecimentos clínicos consequentes da ingestão de alimentos ou água que possam estar contaminados com microrganismos patogênicos como: vírus, bactérias, protozoários e fungos ou pela ingestão de substâncias químicas nocivas à saúde como agrotóxicos, produtos químicos ou metais pesados (Nunes et al., 2018; Draeger, 2018).

Normalmente estes processos infecciosos são acompanhados de problemas digestivos (náuseas, vômitos, diarreia e dores abdominais), mas dependendo do agente etiológicos pode ocorrer quadros mais severos com desidratação grave, diarreia sanguinolenta, insuficiência renal aguda e insuficiência respiratória (Pereira, 2020; Brasil, 2010).

Estes surtos podem ser classificados em processos infecciosos, quando ocorre a ingestão de água ou alimento contaminado com a bactéria patogênica viva e com condições de crescer no trato gastrointestinal (Bernardes et al., 2018). Pode ocorrer na forma de intoxicação mediante a ingestão de toxinas produzidas durante o crescimento de colônias bacterianas nos alimentos e existem casos onde ocorre a toxinfecção caracterizado pela a ingestão do microrganismo patogênico ou suas respectivas toxinas (Bernardes et al., 2018; Souza et al., 2021).

O diagnóstico de doenças veiculadas por alimentos é realizado de acordo com cada caso, pois serão avaliados conforme os sintomas dos acometidos e por exames laboratoriais específicos (Brasil, 2021). Dessa forma, os testes laboratoriais devem estar de acordo com as hipóteses dos possíveis diagnósticos, tendo em vista que existem diversas doenças transmitidas por alimentos (Brasil, 2010).

A sua incidência é mais expressiva em países e regiões subdesenvolvidas, onde o saneamento básico é precário, a água para consumo humano não alcança parâmetros mínimos de qualidade (Santos et al., 2018; Paiva \& Sousa, 2018). Além destes problemas, fatores que envolve o posicionamento geográfico de algumas regiões do planeta também contribuem para o aumento de doenças de origem alimentar, visto que países de clima tropical são mais suscetíveis a proliferação de pragas, microrganismos e formação de toxinas (Draeger, 2018).

A região Nordeste do Brasil é caracterizada por possuir clima tropical e com altas temperaturas o ano todo, é constituída por nove estados e apresenta-se como uma vasta região em termos geográficos, econômicos e demográficos, onde é a segunda região mais populosa do país e é a região brasileira que apresenta um dos mais baixos índices de desenvolvimento social e econômico, fatores estes determinantes para a ocorrência de notificações de surtos por DTA, isto por que, quanto mais baixos são esses índices, mas precárias são as condições de saúde da população (Silva \& Esperidião, 2017; Teixeira, 2018).

Infelizmente ainda muitos destes casos não são notificados, pois boa parte dos acometidos apresentam sintomas leves o que contribui para a não procura por atendimento médico (Malacrida et al., 2017). Muitas das doenças alimentares resultam da associação entre o consumo de alimentos contaminados através da manipulação inadequada e conservação ou distribuição em condições impróprias, é necessário que haja garantia de qualidade do produto desde o campo até a mesa do consumidor (Pereira, 2020).

Órgãos como Agência Nacional de Vigilância Sanitária, no Brasil tem o papel de fiscalizar os estabelecimentos que produzem e comercializam alimentos, assim sua função é promover e proteger a saúde da população, desta forma é possível aumentar o controle sobre a produção de alimentos, por ser esta uma forma de contaminação de alimentos (Patrício et al., 2019; Brasil, 2019). 
O processo de análise de notificação de surto por DTA, pode ser um método considerável para a verificação de fatores sociais e/ou econômicos de uma sociedade em virtude de este refletir a sua real situação de saúde, saneamento básico e as desigualdades sociais e de renda, pois a partir dessa avaliação é possível a elaboração de políticas públicas que possam eliminar ou atenuar problemas relacionados a saúde pública (Silva \& Esperidião, 2017; Santos et al., 2018).

Assim, este trabalho teve como objetivo fazer uma análise epidemiológica do perfil bacteriano envolvido nas Doenças Transmitidas por Alimentos (DTA), na região Nordeste do Brasil para o ano de 2019, e além disso, identificar quais estados da região Nordeste apresentam o maior número de notificações por DTA, assim como investigar os locais e os alimentos onde estes surtos ocorrem com maior frequência.

\section{Metodologia}

Este trabalho é um estudo descritivo, visto que faz uma análise minuciosa e descritiva do objeto de estudo (Apolinário, 2012). É uma pesquisa que consiste em um estudo epidemiológico realizado a partir de dados do Sistema de Informação de Agravos de Notificação (SINAN) referentes aos casos notificados de Doenças Transmitidas por Alimentos (DTA), nos estados da região Nordeste do Brasil ocorridos no ano de 2019.

Os dados epidemiológicos dos surtos de DTA foram organizados em tabelas e analisados de forma qualitativa, através da análise de conteúdo, pois consiste em um conjunto de técnicas de análises das comunicações, onde esta técnica não se trata de um instrumento, mas de um leque de apetrechos; ou, com maior rigor, será um único instrumento, mas marcado por uma grande disparidade de formas e adaptável a um campo de aplicação muito vasto: as comunicações (Bardin, 1977).

As variáveis avaliadas foram: estado da região Nordeste, agente causador do surto, alimento causador do surto, local do surto. Foram excluídas deste estudo as notificações, onde não foi possível a identificação do agente causador do surto.

\section{Resultados e Discussão}

A Tabela 1 abaixo apresenta as informações extraídas do Sistema de Informações de Agravos de Notificações (SINAM), para o Brasil, foram notificados $(n=770)$ surtos relacionados a DTA no ano de 2019, destas notificações $(n=197)$ foram registradas na região Nordeste.

Tabela 1 - Número de notificações de surtos por DTA, para a região Nordeste, para o ano de 2019.

\begin{tabular}{l|c|c}
\hline \multicolumn{1}{c|}{ Ag. Causador } & $\mathbf{N}^{\circ}$ de registros & $\mathbf{( \% )}$ \\
\hline Não foi possível a identificação & 134 & $68 \%$ \\
\hline Bactérias & 58 & $29 \%$ \\
\hline Vírus & 04 & $2 \%$ \\
\hline Protozoários & 01 & $1 \%$ \\
\hline Total & $\mathbf{1 9 7}$ & \\
\hline
\end{tabular}

Fonte: SINAN (2019).

Na Tabela 1 é apresentado o número de notificações de surtos por DTA para a região Nordeste, isto para o ano de 2019, no entanto é importante salientar que estes números revelam apenas uma pequena parcela destes casos, visto que o problema da subnotificação relacionada a este fator ainda é persistente, isto porque muitos dos sintomas apresentados por este tipo de doença são muito semelhantes aos de gripes ou discretas diarreias e vômitos o que favorece para que muitos dos acometidos não 
procurarem assistência médica e vale lembrar que a população mais carente normalmente são as mais afetadas por contaminações alimentares, devido aos hábitos culturais da alimentação e à necessidade de optar por produtos com menor preço, geralmente de pior qualidade e mais contaminados (Malacrida et al., 2017; Draeger, 2018).

Outra situação apresentada na tabela 1 e que precisa ser avaliada, envolve a questão da identificação do agente etiológico, onde os dados expõem um número considerável de casos em que não se consegue fazer a identificação, isto pode ser gerado pela notificação tardia, a ausência de coleta de amostras clínicas e/ou de alimentos em tempo oportuno, ou testes laboratoriais inadequados (Draeger, 2018). A carência destas informações é muito prejudicial para a tomada de decisões que visem atitudes de combate quanto a surtos que envolvam DTA, uma ação importante seria a de informar a comunidade sobre a ocorrência dos surtos e quais são as atitudes necessárias para evitar este tipo de doença, assim como os órgãos públicos passem a agir nos requisitos de fiscalizar e oferecer políticas públicas que sanem ou amenizem este problema (Silva et al., 2017; Guilherme \& Esteves, 2017).

Uma característica também apresentada na tabela 1 e que é muito identificada em trabalhos com este feito, está relacionada com o envolvimento de bactérias na maioria dos casos de DTA. Nota-se que quando comparada com os demais agentes (vírus e protozoários), o número de DTA, onde o agente causador é uma bactéria é bem maior, com isso este trabalho segue a tendência de diversas pesquisas desenvolvidas com este propósito no Brasil (Nunes et al., 2018; Malacrida et al., 2017).

Para a tabela 2 a seguir são apresentados os números de notificações por estado na região Nordeste, onde o agente envolvido no surto referia-se a cepas bacterianas, nota-se a presença significativa de notificações no estado do Pernambuco em relação aos demais, mesmo este apresentando o terceiro maior IDH (Índice de Desenvolvimento Humano), 0,673 entre as regiões onde houve a ocorrência de casos notificados, ficando atrás apenas dos estados o Rio Grande do Norte 0,684 e Ceará 0,682 (Brasil, 2010). Para este número expressivo de surtos por DTA em Pernambuco é preciso a adoção de medidas de fiscalização e controle sobre o comércio de alimentos e a melhoria do saneamento básico, bem como a adoção de políticas públicas para difusão de informação sobre higiene à população (Silva et al., 2017; Ferrari \& Fonseca, 2019).

Tabela 2 - Número de notificações por estados da região Nordeste, onde o agente identificado pelo surto envolvia bactéria, no ano de 2019

\begin{tabular}{l|c|c}
\hline \multicolumn{1}{c|}{ Estado } & $\mathbf{N}^{\circ}$ de notificações & $\mathbf{( \% )}$ \\
\hline Pernambuco & 48 & $83 \%$ \\
\hline Rio Grande do Norte & 02 & $3 \%$ \\
\hline Sergipe & 03 & $2 \%$ \\
\hline Piauí & 01 & $5 \%$ \\
\hline Ceará & 03 & $2 \%$ \\
\hline Paraíba & 01 & \\
\hline Total & $\mathbf{5 8}$ & \\
\hline
\end{tabular}

Fonte: SINAN (2019).

Uma questão interessante sobre estas informações apresentadas na Tabela 2 está relacionada a falta de notificações em alguns estados pertencentes a região Nordeste, isto pode ser advindo de intensas políticas de fiscalização e controle nestes estados quanto a esta problemática ou deficiências nos processos de identificação e notificação destes casos. Isto pode ocorrer devido o perfil epidemiológico dessas doenças ainda ser pouco conhecido, somente alguns estados e/ou municípios dispõem de estatísticas e levantamentos reais sobre os agentes etiológicos mais comuns, outro fator que requer atenção é que doenças transmitidas por alimentos nem sempre são oficialmente notificadas (Malacrida et al., 2017; Guilherme \& Esteves, 2017). 
Para a Tabela 3 adiante são apresentadas as principais bactérias identificadas nos surtos, onde 8 espécies de microrganismos foram identificadas, dentre as mais predominantes foram Escherichia coli, Staphylococcus aureus e Salmonela o que se percebe é que estes agentes ainda continuam sendo os principais envolvidos nos surtos por DTA, no Brasil nos últimos 17 anos (Brasil, 2021; Nunes et al., 2018).

Tabela 3 - Principais bactérias identificadas nos surtos por DTA, para a região Nordeste no ano de 2019

\begin{tabular}{l|c|c}
\hline \multicolumn{1}{c|}{ Bactérias } & $\mathbf{N}^{\circ}$ de identificações & $\mathbf{( \% )}$ \\
\hline Staphylococcus aureus & 08 & $14 \%$ \\
\hline Escherichia coli & 36 & $62 \%$ \\
\hline Clostridium & 02 & $3 \%$ \\
\hline Shiguella & 02 & $3 \%$ \\
\hline Salmonela & 04 & $7 \%$ \\
\hline Bacillus cereus & 03 & $5 \%$ \\
\hline Enterobacter & 01 & $2 \%$ \\
\hline Klebsiela & 02 & $3 \%$ \\
\hline Total & $\mathbf{5 8}$ & \\
\hline
\end{tabular}

Fonte: SINAN (2019).

De acordo com estes organismos pode-se também inferir o padrão por DTA, entre infecção e intoxicação, onde a identificação da presença de organismos como Escherichia coli, Shiguella, Salmonela, Enterobacter e Klebsiela indica a ocorrência de uma infeção, enquanto que a presença de organismos como Staphylococcus aureus, Clostridium e Bacilus cereus, indica uma intoxicação (Bernardes et al., 2018; Malacrida et al., 2017). Portanto o interessante seria procurar um maior controle de medidas higiênico-sanitária, tanto para a armazenagem e transporte de alimentos, assim como para seus manipuladores (Pereira, 2020). As bactérias constituem um grupo microbiano de alta incidência que apresenta ampla diversidade e virulência, o que lhes confere grande importância frente à sua capacidade de provocar danos à saúde humana (Silva et al., 2017).

A tabela 4 mais abaixo apresenta o principal alimento envolvido em surtos por DTA, para a região Nordeste, o que se vê é a participação significativa da água nestes surtos. Isto se deve por ser a água o agente que mais participa nos processos de produção de alimento, ela está presente desde o campo até chegar a mesa do consumidor e nem sempre está água pode apresentar a qualidade necessária para ser envolvida neste processo (Guilherme \& Esteves, 2017; Draeger, 2018).

Um dos grandes problemas em nosso país refere-se à deficiência do saneamento básico sobretudo nas regiões Norte e Nordeste, é isto é tido como um dos principais meios de contaminação das águas para abastecimento humano, o que contribui para a origem de doenças infecciosas, parasitárias e transmitidos principalmente por veiculação hídrica (Santos et al., 2018; Silva \& Esperidião, 2017). 
Tabela 4 - Alimentos apontados como causador do surto por DTA, na região Nordeste para o ano de 2019.

\begin{tabular}{l|c|c}
\hline \multicolumn{1}{c|}{ Alimento } & $\mathbf{N}^{\circ}$ de notificações & $\mathbf{( \% )}$ \\
\hline Água & 36 & $62 \%$ \\
\hline Alimentos mistos & 05 & $9 \%$ \\
\hline Ignorado & 02 & $3 \%$ \\
\hline Frutas ou prod. a base de frutas & 01 & $2 \%$ \\
\hline Leite e derivados & 01 & $2 \%$ \\
\hline Carne bovina in natura & 01 & $2 \%$ \\
\hline Múltiplos alimentos & 10 & $2 \%$ \\
\hline Cereais, farináceos & 01 & $2 \%$ \\
\hline Doces ou sobremesas & 01 & \\
\hline \multicolumn{1}{c}{ Total } & $\mathbf{5 8}$ & \\
\hline \multicolumn{1}{c}{ Fonte SINAN $(2019)}$. \\
\end{tabular}

A Tabela 5 aponta as residências como sendo os locais de maior vulnerabilidade para a ocorrência de surtos. Isto pode ser advindo pelo fato de que muitas residências, ainda utilizam água de fontes alternativas não tratadas para lavar e preparar os alimentos o que pode comprometer a qualidade dos alimentos nas residências e a falta de capacitação dos manipuladores de alimentos quanto as boas práticas de manuseio, armazenamento e preparo adequado de alimentos o que pode ser preocupante, visto que é comum atualmente a comercialização de alimentos através de redes sociais por estabelecimentos que não possuem fiscalização sanitária e muitos destes surgem nas cozinhas de muitas residências (Pereira, 2020; Souza et al., 2021).

Tabela 5 - Locais listados onde ocorreram os surtos por DTA, para a região Nordeste no ano de 2019.

\begin{tabular}{l|c|c}
\hline \multicolumn{1}{c|}{ Local de ocorrência } & $\mathbf{N}^{\circ}$ de notificações & $\mathbf{( \% )}$ \\
\hline Residência & 35 & $60 \%$ \\
\hline Eventos & 02 & $3 \%$ \\
\hline Casos dispersos & 02 & $3 \%$ \\
\hline Outros & 07 & $12 \%$ \\
\hline Padarias/restaurantes & 03 & $5 \%$ \\
\hline Unidade de saúde & 05 & $5 \%$ \\
\hline Creche/escola & 03 & $2 \%$ \\
\hline Alojamento Trabalho & 01 & \\
\hline Total & $\mathbf{5 8}$ & \\
\hline
\end{tabular}

Fonte: SINAN (2019).

\section{Considerações Finais}

O presente trabalho permitiu a identificação do perfil bacteriano envolvido em surtos por DTA, na região Nordeste do Brasil. Para este perfil as bactérias que apresentaram a maiores frequências nos surtos foram: Escherichia coli, Staphylococcus aureus e Salmonela. 
Através das informações obtidas foi possível identificar o estado da região Nordeste que mais apresentou notificações relacionadas a esta problemática, onde Pernambuco foi a região que apresentou uma maior incidência quanto a estes surtos em relação aos demais estados do Nordeste. Vale ressaltar que é preocupante a subnotificação ou inconclusão de informações relacionadas a estes casos, fato este identificado nesta pesquisa, pois a falta de dados impede a captação real da dimensão do problema, o que dificulta a realização de ações de controle.

Outra questão identificada se refere ao alimento que é considerado de maior veiculação para surtos de DTA, o que mais foi citado segundo as informações referia-se à água e apontou as residências como sendo os locais onde mais acontecem estes surtos.

Vale ressaltar que o recorte utilizado para a obtenção das informações, não propiciou a verificação destes casos em outras regiões do Brasil, sendo assim não foi possível avaliar a proporção destes casos a nível nacional.

Portanto as informações apresentadas nesta pesquisa podem servir de apoio para a adoção de políticas necessárias para o controle destas doenças na região Nordeste, assim como maior investimento em ações educativas e legislativas e que trabalhos como este que envolvam outras regiões seria de extrema relevância, pois assim seria possível verificar a realidade de cada região do Brasil.

Seria considerado de relevância a realização de estudos comparativo entre índices de distribuição do saneamento básico, escolaridade e IDH, com os números de notificações de DTA, isto permitiria obter uma maior estimativa e clareza, quanto o real número de notificações e como esses índices podem ou não interferir na qualidade de vida da população.

\section{Referências}

Apolinário, F. (2012). Metodologia da ciência: Filosofia e prática da pesquisa. (2a ed.), Cengage Learning.

Bardin, L. (1977). Análise de conteúdo. (70a ed.), Universitaires de France.

Brasil. (2021). Doenças transmitidas por alimentos. https://www.gov.br/saude/pt-br/assuntos/saude-de-a-a-z/d.

Brasil. (2019). Sistema de Informação de Agravos de Notificação. http://portalsinan.saude.gov.br/surto-doencas-transmitidas-por-alimentos-dta.

Bernardes, N. B., et al (2018). Intoxicação alimentar um problema de saúde pública. Id on Line Rev. Mult. Psic. ,12 (42), $894-906$.

Brasil. (2010). Instituto Brasileiro de Geografia e Estatística. https://cidades.ibge.gov.br/brasil/se/panorama.

Brasil. (2010). Manual Integrado de Prevenção e Controle de Doenças Transmitidas por Alimentos. https://bvsms.saude.gov.br/bvs/publicacoes/manual_ integrado_vigilancia_doencas_alimentos.pdf $>$.

Draeger, C. L. (2018). Incidência das doenças transmitidas por alimentos no Brasil: uma análise de 2007 a 2017. 2018. $98 \mathrm{f}$. Tese de Doutorado - Universidade de Brasília, Brasília.

Ferrari, A. M., \& Fonseca, R. V. (2019). Conhecimento de consumidores a respeito de doenças transmitidas por alimentos. UNESC em revista, 3 (1), 01-12.

Guilherme, D. L., \& Esteves, D. C. (2017). Doenças transmitidas por alimentos e água. Conexão Eletrônica, 14, $390-401$.

Malacrida, M. A., et al (2017). Perfil epidemiológico das doenças bacterianas transmitidas por alimentos no Brasil. Revista de Ciência Veterinária e Saúde Pública, 4, 158-162.

Nunes, P. L. G., et al (2018). Uma breve caracterização dos surtos de doenças transmitidas por alimentos no estado do Ceará no período de 2014 a 2016 . Revista interdisciplinar em ciências da saúde e biológicas, 2 (2), 1-11.

Pereira, M. B. (2020). Percepções de risco sobre doenças transmitidas por alimentos de manipuladores de alimentos em restaurantes: exploração por abordagem qualitativa. 2020. 107f. Dissertação de Mestrado - Universidade Estadual de Campinas, Faculdade de Ciências Aplicadas, Limeira, SP.

Patricío, V. C., et al (2019). Doenças alimentares: Relação Vigilância Sanitária - Epidemiologia. Cadernos Esp/CE, 13 (2), $94-108$.

Paiva, R. F. P. S. \& Souza, M. F. P. (2018). Associação entre condições socioeconômicas, sanitárias e de atenção básica e a morbidade hospitalar por doença de veiculação hídrica no Brasil. Caderno Saúde pública, 34 (1).

Souza, J. F., et al (2021). Estudo retrospectivo de surtos de doenças veiculadas por alimentos, na região Nordeste e estado do Maranhão, no período de 2007 a 2019. Research, Society e Development, 10 (1).

Santos, F. F. S., et al (2018). O desenvolvimento do saneamento básico no Brasil e as consequências para a saúde pública. Revista brasileira de meio ambiente, 4 (1), 241-251. 
Research, Society and Development, v. 10, n. 11, e428101119855, 2021

(CC BY 4.0) | ISSN 2525-3409 | DOI: http://dx.doi.org/10.33448/rsd-v10i11.19855

Silva, J. C. G., et al (2017). Incidência de doenças transmitidas por alimentos (DTA) no estado de Pernambuco, um acompanhamento dos dados epidemiológicos nos últimos anos. Revista Cadernos de Educação Ciências Biológicas e da Saúde, 3 (1), 23-34.

Silva, V. A., \& Esperidião, F. (2017). Saneamento básico e seus impactos na mortalidade infantil e no desenvolvimento econômico da região Nordeste. Scientia Plena, 13 (10).

Teixeira, K. H. (2018). Uma análise da estrutura espacial dos indicadores socioeconômicos do Nordeste brasileiro (2000-2010). Revista EURE (Santiago), 44 (131). 